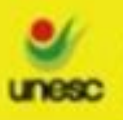

\title{
AS PRÁTICAS DE ALFABETIZAÇÃO NA EJA NA VISÃO DAS PROFESSORAS DOS ANOS INICIAIS DO ENSINO FUNDAMENTAL EM UM MUNICÍPIO DA
}

\author{
AMREC
}

\section{LITERACY PRACTICES IN EJA IN THE PERSPECTIVE OF EARLY ELEMENTARY SCHOOL TEACHERS IN AN AMREC'S MUNICIPALITY}

\section{Sibele Guedin Custódio ${ }^{1}$}

Mirozete Iolanda Volpato Hanoff ${ }^{2}$

\begin{abstract}
RESUMO: A presente pesquisa tem como objetivo geral conhecer as metodologias que embasam as práticas pedagógicas das professoras alfabetizadoras na Educação de Jovens e Adultos (EJA) em um município pertencente a região da $\mathrm{AMREC}^{\mathbf{3}}$. A alfabetização no Brasil, nos anos iniciais do ensino fundamental e na EJA, durante muitos anos aconteceu seguindo a concepção tradicional de ensino e aprendizagem, ou seja, iniciava com as letras do alfabeto e palavras soltas e sem sentido para os alunos. Entretanto, há mais de duas décadas os estudiosos sobre o tema no Brasil têm mostrado que existem outros métodos para alfabetizar e que devem ser utilizados em ambas modalidades e que atendem mais as necessidades da sociedade e tem mais significado para os alunos. Diante desse contexto buscou-se, também, identificar a concepção pedagógica que embasa a prática das professoras, refletir sobre o perfil do professor e do aluno nesta modalidade e analisar as metodologias utilizadas pelas professoras da EJA no processo de alfabetização. Para isso, a pesquisa está sustentada em autores como: Freire (1990), Schwartz (2010), Cortada (2013), Haddad e Di Pierro (2000) e Leal (2010). A pesquisa é exploratória descritiva e de natureza básica, em que foram entrevistadas duas professoras da EJA do município, que atuam nos anos iniciais. A entrevista aconteceu de forma não estruturada. A pesquisa aponta que mesmo as metodologias utilizadas sejam distintas, as professoras buscam em alguns momentos considerar as práticas de letramento dos seus alunos no processo de alfabetização.
\end{abstract}

PALAVRAS CHAVE: EJA. Alfabetização e letramento. Práticas.

ABSTRACT: The present research has the general objective of knowing the methodologies that support the pedagogical practices of literacy teachers in Youth and Adult Education (EJA) in a municipality that belongs to the AMREC ${ }^{3}$ region. Literacy in Brazil, in the early years of elementary school and in EJA, for many years took place following the traditional

\footnotetext{
${ }^{1}$ Graduada em Pedagogia/UNESC - Universidade do Extremo Sul Catarinense. guedinsibele@ gmail.com

2 Graduada em Pedagogia, Especialista em Fundamentos da Educação /UNESC - Universidade do Extremo Sul Catarinense.mvh@unesc.net

${ }^{3}$ Associação dos Municípios da Região Carbonífera

Saberes Pedagógicos, Criciúma, v. 5, n³, setembro/dezembro 2021.- Curso de Pedagogia- UNESC
} 
concept of teaching and learning, that is, it starts with the letters of the alphabet and aleatory and meaningless words for students. However, for more than two decades, scholars on the subject in Brazil have shown that there are other methods for literacy and that they should be used in both modalities and that they meet the needs of society more and have more meaning for students. In this context, it was also sought to identify the pedagogical concept that underlies the practice of teachers, reflect on the profile of the teacher and the student in this modality and analyze the methodologies used by EJA teachers in the literacy process. For this, the research is supported by authors such as: Freire (1990), Schwartz (2010), Cortada (2013), Haddad and Di Pierro (2000) and Leal (2010). The research is exploratory, descriptive and has a basic nature, where two teachers from EJA in the municipality, who work in the initial years, were interviewed. The interview happened in an unstructured way. The research shows that even though the methodologies used are different, teachers sometimes try to consider the literacy practices of their students in the literacy process.

KEYWORDS: EJA. Literacy. Practices.

\section{INTRODUÇÃO}

A educação de Jovens e Adultos (EJA) possui uma longa trajetória no contexto histórico brasileiro. Essa modalidade de ensino iniciou no período do Brasil colonial e já passou por várias nomenclaturas e concepções. Ao longo dos anos, muitas mudanças ocorreram, tanto no contexto histórico quanto nas estruturas e ensino da EJA. Diante disso, pode-se perceber a importância de todas essas mudanças para a construção da Educação de Jovens e Adultos da atualidade.

A necessidade de realizar esta pesquisa surgiu a partir das aulas de Processos Pedagógicos da Educação de Jovens e Adultos, ministrada no curso de Pedagogia da Universidade do Extremo Sul Catarinense - UNESC. Durante o semestre, estudamos os alunos da EJA que chegam à escola com uma grande bagagem de vivências e experiências. Desta forma, esse sujeito precisa de uma maneira própria e diferenciada de se alfabetizar, diferente das crianças que estão tendo seu primeiro contato com o mundo da escrita.

Nos dias atuais, entende-se que a alfabetização que acontecia de maneira tradicional não atende mais às expectativas e interesses dos alunos, independente da modalidade de ensino que frequentam. É imprescindível assim, que o letramento caminhe imbricado com a alfabetização, pois mais do que ser alfabetizado (reconhecer os códigos escritos), é preciso ser letrado, ou seja, aplicar esses conhecimentos no seu meio social.

Saberes Pedagógicos, Criciúma, v. 5, n³ , setembro/dezembro 2021.- Curso de Pedagogia- UNESC 
Desse modo, a problemática desta pesquisa se define a partir do questionamento: Como ocorrem as práticas de alfabetização na Educação de Jovens e Adultos dos anos iniciais do ensino fundamental? Por sua vez, o objetivo geral fundamenta-se em: Conhecer as metodologias que embasam as práticas pedagógicas das professoras alfabetizadoras na Educação de Jovens e Adultos (EJA) em um município da AMREC ${ }^{3}$.

Para alcançar o objetivo geral elencou-se como objetivos específicos: identificar a concepção pedagógica que embasa a prática das professoras; refletir sobre o perfil do professor e do aluno da EJA; reconhecer os obstáculos que ocorrem no período de alfabetização.

Assim, para alcançarmos os objetivos propostos, a pesquisa foi dividida em três seções: a primeira delas, denominada de EJA no Brasil: histórico e função do professor e do aluno, aponta os principais marcos históricos da EJA e busca refletir sobre o perfil dos alunos e professores desta modalidade de ensino; na segunda seção, Alfabetização e letramento na $E J A$, faz-se uma retomada no histórico da alfabetização e letramento, traz seu conceito e por fim, aponta as práticas de alfabetização e letramento utilizadas na EJA. Já na terceira seção, Metodologia, Apresentação e Análise dos Dados, aparece a apresentação dos dados da pesquisa, alisados à luz do referencial teórico.

\section{EJA NO BRASIL: HISTÓRICO E FUNÇÃO DO PROFESSOR E DO ALUNO}

A Educação de Jovens e Adultos (EJA) nem sempre teve essa nomenclatura, pois ao longo dos anos essa modalidade passou por significativas mudanças. Segundo Cortada (2013), a Educação de Jovens e Adultos iniciou no Brasil Colônia, principalmente com a chegada dos Jesuítas ao país. Estes, por sua vez, tinham como objetivo principal catequisar os índios e ensinar a leitura desse catecismo aos colonos, a fim de que mais tarde os mesmos pudessem cumprir as tarefas e exigências feitas pelo Estado.

Entretanto, após a expulsão dos jesuítas, os autores Haddad e Di Pierro (2000) destacam que o ensino passou por uma desorganização. Em 1890, o Censo Demográfico apontou que cerca de $80 \%$ da população brasileira era analfabeta. Desta forma, Albuquerque (2010) pontua que o Brasil começou a ser considerado atrasado comparado a outros países. Saberes Pedagógicos, Criciúma, v. 5, n³, setembro/dezembro 2021.- Curso de Pedagogia- UNESC 


\section{SABERES PEDAGÓGICOS}

Revista do Curso de Graduaçào de Pedagogia - Unesc

ISSN 2526-4559

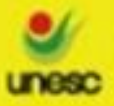

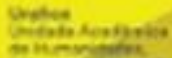

Assim, a Educação de Jovens e Adultos passou a ter maior relevância em 1932 com a Cruzada Nacional da Educação, que de acordo com Cortada (2013) tinha como finalidade a erradicação do analfabetismo no país e como objetivo, acabar com o analfabetismo em 10 anos.

Segundo Haddad e Di Pierro (2000), no final da década de 50, a Educação de Jovens e Adultos passou a receber muitas críticas, que iam desde os setores administrativos e financeiros até a proposta pedagógica. No aspecto pedagógico a maior crítica era sobre o aspecto superficial do aprendizado, o curto período da alfabetização e o método de ensino pouco adequado para a população adulta das diferentes regiões do país. Todas essas críticas levaram a consolidação de um novo paradigma pedagógico para a EJA no Brasil, surgindo então, um dos maiores mestres da nação brasileira, o educador pernambucano Paulo Freire.

Com a mudança de paradigma, o analfabetismo, que antes era tratado como causa da pobreza e da marginalização, passou a ser visto como resultado da pobreza, sendo este, fruto de uma estrutura social não-igualitária. Freire (2002, p. 11), propôs um método de alfabetização para adultos, cujo princípio básico era que: "a leitura do mundo precede a leitura da palavra". Paulo Freire eliminou o uso das cartilhas e desenvolveu um procedimento pedagógico que ficou conhecido como "Métodos Paulo Freire de Alfabetização", o qual o objetivo primeiro era levar o aluno a assumir-se como autor de sua aprendizagem, como um ser capaz e responsável, antes mesmo de iniciar o aprendizado da escrita.

O método de Paulo Freire para alfabetização foi utilizado entre os anos de 1961 e 1964, mas acabaram sendo extintos com o golpe militar em março de 1964. Com o golpe militar de 1964, a Educação de Jovens e Adultos sofreu um rompimento. Haddad e Di Pierro (2000) destacam que os movimentos educacionais foram reprimidos e censurados. Durante esse período, o governo lança o MOBRAL (Movimento Brasileiro de Educação), que, segundo Cortada (2013), não havia preocupação alguma em relação a transformação de um sujeito ativo e crítico, ou seja, o movimento tinha como objetivo apenas acabar com o analfabetismo, não buscava uma reflexão desse sujeito na sua prática e no meio social.

Em 1971, com a promulgação da LDB 5692/71, é que a educação de adultos passou a ser tratada para além da alfabetização, visando suprir a "escolarização regular para jovens e adultos que não haviam concluído seus estudos na idade regular”. Em 1973, o MEC

Saberes Pedagógicos, Criciúma, v. 5, n³ , setembro/dezembro 2021.- Curso de Pedagogia- UNESC 
criou o Departamento de Ensino Supletivo (DESU), por meio do Decreto 71.737, com a proposta de ampliar o ensino supletivo no país.

De acordo com Freire (apud GADOTTI, 1979), mesmo com todas as mudanças e propostas que aconteceram até o final da década de 80, os dados da UNESCO apontavam, que o número de analfabetos no mundo tinha aumentado e o Brasil aparecia na lista como um dos responsáveis por contribuir com esse aumento. Com o fim do regime militar, por volta do início dos anos 90, surgiram no Brasil, novos estudos e pesquisas sobre o processo de alfabetização com bases na linguística e na psicologia. Esses estudos tiveram como suporte o trabalho da argentina Emília Ferreiro, cujas concepções trouxeram aos professores alfabetizadores, indicações de como poderia acontecer a alfabetização sem utilizar o método da silabação. Cortada (2013) destaca ainda, que nesse mesmo período começou-se a ouvir falar sobre letramento.

Desde então, nas aulas de alfabetização, procurou-se ampliar o universo linguístico, utilizando-se de diferentes tipos de textos como os jornais e enciclopédias, às receitas e embalagens. Essas práticas, em consequência, contribuíram para ampliação de materiais didáticos para a aprendizagem da escrita.

Em 1996, a Educação de Jovens e Adultos ganhou, finalmente, um lugar de destaque na história da educação brasileira, com a publicação da nova Lei de Diretrizes e Bases da Educação Nacional - Lei $n^{\circ} 9.394$ /96, quando passou a fazer parte da modalidade da Educação Básica, por meio de dois artigos:

Art. 37. A educação de jovens e adultos será destinada àqueles que não tiveram acesso ou continuidade de estudos no ensino fundamental e médio na idade própria. $\S 1^{\circ}$ Os sistemas de ensino assegurarão gratuitamente aos jovens e aos adultos, que não puderam efetuar os estudos na idade regular, oportunidades educacionais apropriadas, consideradas as características do alunado, seus interesses, condições de vida e de trabalho, mediante cursos e exames. $\S 2^{\circ} \mathrm{O}$ Poder Público viabilizará e estimulará o acesso e a permanência do trabalhador na escola, mediante ações integradas e complementares entre si. Art. 38. Os sistemas de ensino manterão cursos e exames supletivos, que compreenderão a base nacional comum do currículo, habilitando ao prosseguimento de estudos em caráter regular. $\S 1^{\circ}$ Os exames a que se refere este artigo realizar-se-ão: I - no nível de conclusão do ensino fundamental, para os maiores de quinze anos; II - no nível de conclusão do ensino médio, para os maiores de dezoito anos. $\S 2^{\circ}$ Os conhecimentos e habilidades adquiridos pelos educandos por meios informais serão aferidos e reconhecidos mediante exames. (BRASIL, 1996, p. 13) 
A LDB 9394/96, ampliou os limites de idade para o aluno entrar na EJA, oferecendo ingresso no ensino fundamental a partir dos 15 anos e no ensino médio a partir dos 18 anos e elegeu o Poder Público para proporcionar Educação Básica à toda população brasileira. Essa lei deixou explícito também, que a educação de jovens, adultos e idosos é pautada numa diversidade cultural e sociológica, e por isso deve respeitar as necessidades e características regionais e locais do país.

Assim, encerra-se aqui a breve discussão sobre o histórico da EJA no Brasil, em que se pontuaram os principais marcos que construíram sua trajetória. Em seguida, conheceremos um pouco sobre quem são os alunos que procuram a EJA e qual o papel do professor que vai acolher esse aluno que está voltando para a escola.

\subsection{A EJA e seus alunos}

A Educação de Jovens e Adultos possui divergências e singularidades em relação ao ensino regular. Os alunos dessa modalidade trazem consigo experiências, princípios e valores já constituídos, entretanto, retornam à escola em busca de oportunidades e maior autonomia. Cortada (2013) aponta que os alunos da EJA são indivíduos de diferentes tempos e culturas. Deste modo, a sala de aula da Educação de Jovens e Adultos possui sujeitos de idades diferenciadas, níveis socioeconômicos distintos e expectativas variadas.

Diferente do ensino regular, a EJA traz atributos próprios dessa modalidade de ensino. Assim sendo, uma grande característica da EJA é sua heterogeneidade. Homens, mulheres, jovens que estão iniciando sua caminhada, pessoas idosas, que já possuem experiência, trabalho, família e valores constituídos, representam o público-alvo desse ensino.

Os jovens, adultos e também os idosos da EJA possuem um vasto campo de conhecimento que irá auxiliá-lo nesse processo de alfabetização. Deste modo, mesmo não compreendendo o processo de leitura e escrita, esse educando está em constante contato com essas práticas de letramento.

Segundo Barros (2011, p. 35), “Inúmeras experiências apontam para a necessidade de se pensar a especificidade desses alunos e de se superar a prática de trabalhar Saberes Pedagógicos, Criciúma, v. 5, n³ , setembro/dezembro 2021.- Curso de Pedagogia- UNESC 
com eles da mesma forma que se trabalha com crianças e adolescentes”. Em outras palavras, é preciso "ver" a EJA com outros olhos, com toda a especificidade que essa modalidade requer.

Barros (2011) acentua ainda que os jovens e adultos podem sofrer uma "dupla exclusão". Num primeiro momento em idade escolar, quando não conseguiram ter a oportunidade de acesso à escola. E agora, na idade adulta, retornando à escola e vivendo sentimentos negativos, de inferioridade e vergonha, acarretando assim, uma possível dificuldade e barreira no seu processo de aprendizagem. A falta de um olhar diferenciado do educador e ou da equipe escolar perante esses alunos poderá, muitas vezes, corroborar ainda mais para o abandono e a evasão escolar desses sujeitos.

Como é possível perceber, os alunos que hoje frequentam a Educação de Jovens e Adultos possuem diferentes motivos que resultam no seu retorno a escola, seja pela autonomia perante a leitura e escrita cada vez mais presente do dia-a-dia ou em busca de um emprego melhor e novas oportunidades. Todas essas diversidades fazem parte da sala de aula da EJA, para tanto, é preciso valorizar esse espaço de aprendizagem e a socialização em busca de objetivos em comum.

\subsection{O papel do professor da EJA}

O educando vem para a escola carregando vastos conhecimentos e o professor tem um importante papel na permanência desse aluno na escola. No território da EJA, mesmo com objetivos semelhantes aos do ensino regular (que os alunos saiam dali compreendendo o processo de leitura e escrita), a forma que serão ensinados os conteúdos precisam ser diferentes, iniciando pela construção do seu planejamento. Como já foi visto, os sujeitos que frequentam essa modalidade, possuem um vasto conhecimento de mundo, mesmo não compreendendo os códigos escritos. Deste modo, o planejamento precisa ser construído em cima dessa realidade. $\mathrm{O}$ indivíduo é um ser social que está em constante interação com o meio. Considerar tudo que ele já conhece, envolve o aluno ainda mais em todo processo de ensino-aprendizagem. 
O professor precisa ter um olhar diferenciado ao trabalhar na classe da EJA. O docente será o mediador nesse processo, estimulando esses adultos a manterem a sua jornada na escola e alcançando esses objetivos. Logo, necessitará de práticas diferentes das que, por exemplo, utiliza com crianças, caso contrário, acaba acarretando sua metodologia em um ensino infantilizado.

O professor da EJA precisa, também, lidar constantemente com a baixa autoestima encontrada em muitos educandos de EJA - suas trajetórias de dificuldades de toda ordem, suas experiências, muitas vezes, traumáticas com uma escola excludente e as adversidades que enfrentam para frequentar a sala de aula são grandes barreiras na vida de muitos alunos. Segundo Cortada (2013), por ser a EJA um território bastante diversificado, exige do pedagogo uma compreensão mais ampla, como: respeito ao tempo, a trajetória e a faixa etária dos discentes, não esquecendo que aquele aluno é um indivíduo que tem família, trabalho, e têm objetivos e aspirações que pretendem alcançá-los frequentando a sala de aula da Educação de Jovens e Adultos.

Encerra-se essa parte sobre o papel do professor da EJA com uma frase deixada pelo mestre Paulo Freire: "Ninguém ignora tudo. Ninguém sabe tudo. Todos nós sabemos alguma coisa. Todos nós ignoramos alguma coisa, por isso aprendemos sempre". (FREIRE, 1989, p. 39)

\section{A ALFABETIZAÇÃO NA EJA.}

A EJA é uma modalidade de ensino ainda muito nova no campo da Educação, mas ao falar em Educação de Jovens e Adultos, remete-se ao conceito de alfabetização, uma vez que, grande parcela dos alunos da EJA busca compreender o processo de alfabetização e assim buscar melhores condições e possibilidades na sociedade. Nesse sentido, buscou-se nesta seção conhecer o histórico da alfabetização e letramento na EJA, o seu conceito e as práticas pedagógicas utilizadas pelas professoras da EJA.

\subsection{Retomando o histórico da alfabetização e do letramento na EJA}


Tratando-se do processo de alfabetização, nem sempre houve uma preocupação com a maneira a qual o sujeito aprende. O objetivo esteve sempre muito voltado para a codificação e decodificação do conteúdo, centralizado no ensino tradicional, em que conhecendo o sistema alfabético e justando as letras, o indivíduo já estava alfabetizado.

Entretanto, começou-se a verificar que ser apenas alfabetizado não bastava, uma vez que, muitas pessoas eram tidas como alfabetizadas, mas não faziam uso desse conhecimento, incorporando essas práticas em suas realidades, no seu dia a dia.

Diferente, por exemplo, dos alunos que frequentam as salas de aula da EJA, esses por sua vez, tem contato com as mais diversas práticas de letramento, e isto se deve a todo o contato e a relação do sujeito na sociedade. Esses educandos buscam na EJA serem alfabetizados e assim, aprenderem a ler e escrever, pois o letramento eles já trazem consigo. Deste modo, Soares pontua que:

Quando à mudança na maneira de considerar o significado do acesso à leitura e a escrita em nosso país da mera aquisição da "tecnologia" do ler e do escrever à inserção nas práticas sociais de leitura e escrita, de que resultou o aparecimento do termo letramento ao lado do termo a alfabetização. (SOARES, 2001, p. 21)

A autora indica, dessa forma, que a partir do momento em que se substituiu àquela visão meramente tradicional, em que o sujeito é passivo, e que realiza apenas uma cópia, muda-se a forma de pensar a alfabetização. Deste modo, a aprendizagem é construída e o aprendiz assume um papel de protagonista.

Essa preocupação com a intencionalidade com que a alfabetização está acontecendo, fica explícito também com o Censo demográfico. A pesquisa, inicialmente, perguntava se o indivíduo sabia escrever o seu nome, com esse critério era definido o sujeito alfabetizado e o não alfabetizado. Entretanto, o Censo passou a utilizar outra estratégia, assim era considerado alfabetizado aquele que conseguia ler e escrever um bilhete simples.

Por meio do próprio Censo é possível perceber uma maior preocupação já em relação a esse termo ainda muito desconhecido, o letramento. Aqueles que eram alfabetizados precisavam escrever um bilhete, já fazendo uso das práticas sociais em que estava inserido. A partir de então, não se tratava mais de uma escrita mecânica ou decorada do seu nome, havia compreensão do sentido da escrita por parte do sujeito.

Saberes Pedagógicos, Criciúma, v. 5, n³3, setembro/dezembro 2021.- Curso de Pedagogia- UNESC 
Segundo Albuquerque e Ferreira (2008, p. 427), "a partir da década de 1980, a concepção de alfabetização como ensino das habilidades de codificação e decodificação, desenvolvida por meio de práticas pedagógicas que priorizavam a memorização de sílabas e/ou palavras e/ou frases soltas, passou a ser amplamente criticado". Muitas mudanças ocorreram no sentido de alfabetizar. O que muitas vezes era visto apenas como a memorização do sistema alfabético passou a ter uma intencionalidade. Com o surgimento do termo alfabetização, os conhecimentos dos alunos que frequentam o território da EJA surgem como uma forma de contribuir para a sua aprendizagem, já que agora essa aprendizagem tem um significado para eles, trabalhando assim uma alfabetização na perspectiva do letramento.

\subsection{Conceituando alfabetização e letramento}

Segundo Albuquerque (2010) alfabetizar é ensinar a ler e escrever, podendo este processo envolver crianças, jovens ou adultos. Este conceito de alfabetização, segundo a autora, está voltado ao processo de leitura e escrita dos diferentes sujeitos. Trata-se da codificação e decodificação dos códigos escritos. Nesse processo, não necessariamente há uma compreensão ou interpretação do que está sendo lido ou aprendido.

Já o dicionário Aurélio (2010) traz o conceito de letramento como as condições que o indivíduo tem de utilizar-se da leitura e da escrita. Muitas vezes, o indivíduo é letrado, porém, não é alfabetizado, pois ao ir em um supermercado reconhece marcas como Cocacola e Omo, mas isso se deve às suas experiência e vivências na sociedade onde está situado.

Freire (1990) pontua que a alfabetização é um tema muito importante e que merece atenção. Ressalta ainda que achava uma grande injustiça os homens e as mulheres que não sabiam ler e que essa injustiça estava relacionada aos direitos dessas pessoas tomarem suas próprias decisões. O autor aponta ainda que as pessoas alfabetizadas tinham o pensamento de que os que não sabiam ler e escrever não podiam tomar decisões sozinhas.

Segundo a estudiosa do processo de alfabetizar no Brasil, Magda Soares, dizer que alguém aprendeu a ler e a escrever, não quer dizer que tenha se alfabetizado. Magda segue dizendo ainda, que (...) alfabetização é o processo pelo qual se adquire o domínio de um código e das habilidades de utilizá-lo para ler e para escrever, ou seja: o domínio da Saberes Pedagógicos, Criciúma, v. 5, n³, setembro/dezembro 2021.- Curso de Pedagogia- UNESC 
tecnologia - do conjunto de técnicas - para exercer a arte e a ciência da escrita. (...) Ao exercício efetivo e competente da tecnologia da escrita denomina-se letramento. (SOARES, 2003, p. 91).

Percebe-se então, que há uma espécie de hibridação entre alfabetizar e letrar, já que a alfabetização só terá sentido se for associada ao letramento - ou seja, aprender a fazer e fazer o que aprendeu. Enquanto a alfabetização é o aprendizado do processo da leitura e da escrita, o letramento é a prática cotidiana desse mesmo processo. Uma vez alfabetizado, o indivíduo deve ter adquirido a capacidade de entender o que leu ou escreveu, além de concordar ou discordar com certas fontes com que se depara no dia-a-dia.

A pessoa letrada não é aquela que domina a leitura e/ou escrita, mas sim aquela que utiliza essas práticas no seu cotidiano. O sujeito letrado reconhece marcas, produtos de um supermercado e até os itinerários representados nas rodoviárias. Essas percepções estão relacionadas às aprendizagens e vivências adquiridas longo de sua vida. Verifica-se assim, que a diferença da alfabetização na perspectiva do letramento é a utilização e a prática da leitura e escrita, correspondendo assim às demandas cada vez maiores na sociedade, onde cada indivíduo está inserido.

Em vista disso, percebe-se que o sujeito alfabetizado é aquele que tem domínio dos códigos escritos e não consegue fazer uso daquele conhecimento, ou seja, conhece e compreende o sistema alfabético, porém não o consegue interpretar, desconhecendo assim o significado do que leu. Deste modo, o letrado compreende o seu entorno, mesmo não fazendo uso da leitura e da escrita, interpreta o mundo ao seu redor e integra a cultura letrada, participa e interage com a sociedade e com os indivíduos que nela atuam, porém, o sistema alfabético é algo desconhecido para ele.

Leal (2003) pontua que antigamente acreditava-se que memorizando o sistema alfabético, seria possível ler e escrever diversos textos. Em contrapartida, a autora afirma que, de acordo com as pesquisas realizadas, as pessoas em níveis de escolarização mais elevados, muitas vezes, não conseguem fazer uso da leitura e escrita para finalidades básicas do dia-a-dia, como compreender a regra de um jogo, por exemplo.

Nesse sentido, fica claro que não basta simplesmente fazer a leitura do que está exposto, é preciso interpretar as regras, analisando em que elas se aplicam. É possível Saberes Pedagógicos, Criciúma, v. 5, n³, setembro/dezembro 2021.- Curso de Pedagogia- UNESC 
compreender assim, que alfabetizar, na perspectiva do letramento, é aplicar os conhecimentos, interpretando-os, fazendo relações e utilizando-os no dia-a-dia, no trabalho e no contexto onde está inserido.

\subsection{As práticas pedagógicas de alfabetização e letramento na EJA}

Uma das grandes necessidades da Educação de Jovens e Adultos, atualmente, é alfabetizar na perspectiva do letramento, ou seja, além do sujeito ter domínio do sistema alfabético, é preciso saber fazer uso nas suas práticas sociais. A sociedade contemporânea exige cada vez mais um sujeito ativo e crítico, não basta apenas ser alfabetizado, é preciso ser letrado.

A partir do momento em que as pessoas vão se alfabetizando, surge uma nova necessidade, ou seja, as pessoas aprenderam a ler e escrever, mas não necessariamente estão praticando esse conhecimento. Nesse sentido, surge o letramento, a fim de buscar sentido e significado a esse conhecimento.

Segundo Soares (2006) é preciso desenvolver duas habilidades em relação ao mundo da leitura e da escrita. A primeira delas é o domínio do sistema alfabético, já a segunda está relacionada às competências para fazer uso dessa escrita por meio do letramento. Desta forma, é fundamental que a alfabetização e o letramento caminhem juntos, para assim realizar-se práticas efetivas em relação ao ensino da leitura e da escrita com os alunos da EJA.

Leal (2010) destaca que os jovens e adultos da EJA possuem experiências de letramento variados, o que se deve a sua experiência de vida. Por sua vez, somente essas experiências de letramento não são suficientes para desenvolver autonomia no sujeito em relação à leitura e escrita, fazendo com que esses jovens e adultos retornem à escola, a fim de garantir essa aprendizagem que em outro momento não foi possível.

O autor enfatiza que alfabetizar "letrando" requer uma ruptura com as abordagens tradicionais de ensino, estas por sua vez dão enfoque ainda na memorização, valorizando o estudante passivo, voltado para a transmissão daquele conhecimento. Albuquerque (2007) acrescenta que a maioria dos alunos da EJA já vivenciou essa forma de Saberes Pedagógicos, Criciúma, v. 5, n³, setembro/dezembro 2021.- Curso de Pedagogia- UNESC 
ensino de maneira tradicional, que primeiro ensina o aluno a "codificar" e "decodificar", fazendo uso dos métodos de alfabetização, em que só depois era utilizado a leitura e escrita em atividades. A autora, então, destaca a importância da utilização de novos métodos de alfabetização, a fim de garantir uma aprendizagem efetiva.

Sobre os métodos e as práticas pedagógicas utilizadas pelos professores da EJA, Pinto (1994, p.86) aponta que "o problema do método é capital na educação de adultos”, haja visto que estes alunos retornam para a escola trazendo um cabedal de conhecimentos e saberes experimentados durante sua vida. Percebe-se na fala do autor acima citado que o professor da EJA devem adequar suas práticas educativas partindo da realidade do aluno, do seu trabalho, das suas relações sociais, suas crenças, necessidades, jamais esquecendo que os mesmos já possuem uma história de vida construída em contextos sociais.

A autora Telma Ferraz Leal (2010) no capítulo 4 do seu livro “Alfabetizar Letrando na EJA" destaca o trabalho com textos como um dos principais objetivos didáticos para a alfabetização na EJA, pois, segundo ela, os textos ampliam o reportório de palavras e de temáticas nos alunos.“ Despertar o desejo pela leitura, levando os estudantes à buscarem novos textos, criarem intimidade com diferentes gêneros discursivos, é uma meta central no processo de alfabetização”. (LEAL, 2010, p.75)

A autora, no seu texto, sugere também, diversas práticas para os professores trabalharem com textos, as quais são: leitura cotidiana pelo professor de um texto em voz alta - esse texto pode ser uma música, uma poesia, uma notícia do jornal da cidade, salmo bíblico, biografia de um artista conhecido, uma receita culinária, uma receita médica, entre tantos outros, procurando atender os interesses e necessidades cognitivas, culturais e sociais dos alunos da EJA. Complementa sua sugestão lembrando que, diariamente, após cada leitura, o professor deve oportunizar aos educandos a interpretação e discussão do mesmo, a fim de alcançar o objetivo proposto para o tema.

Para Albuquerque (2007), além de aprender o sistema alfabético, eles deverão ser capazes de utilizar esse domínio para auxiliar nas questões do dia-a-dia, como ler a bula de um remédio, preencher um cheque, ler sua carteira de trabalho, demandas que crescem cada vez mais e só são possíveis por meio da alfabetização e do letramento. 
Os jovens e adultos da EJA, mais do que retornarem à escola em busca de melhores oportunidades e possibilidades, precisam encontrar nela esse espaço de mudança em busca de sua autonomia e emancipação perante a cultura alfabetizada e letrada, espaço de diálogo e trocas de experiências e conhecimentos. Mais do que estar na EJA, é preciso vivêla, buscando uma reconstrução da aprendizagem e da visão que tinha da escola, novos significados e interpretações para o que está ao seu redor.

\section{METODOLOGIA, APRESENTAÇÃO E ANÁLISE DE DADOS}

Com este trabalho de pesquisa buscou-se compreender como acontece as práticas de alfabetização nos anos iniciais do ensino fundamental, na Educação de Jovens e Adultos em um município pertencente a região da AMREC. Esse tipo de estudo, de caráter científico, necessitou de uma metodologia específica, capaz de permitir que se aproxime a proposição com o problema, trazendo com detalhes ideias ou descobertas apresentadas pelo pesquisador (GIL, 2002).

Nesse sentido, trata-se de uma pesquisa de cunho qualitativo, uma vez que os dados analisados apresentam a forma como as professoras realizam as práticas de alfabetização e letramento na EJA. Ao levar em consideração sua natureza, trata-se de uma pesquisa básica, pois diante dessas experiências não houve qualquer tipo de intervenção prática, apenas foram analisados os dados colhidos na pesquisa. (SANTOS; SANTOS, 2010)

Quanto a metodologia, a pesquisa se constituiu exploratória e descritiva. Exploratória no sentido de aprofundar mais sobre o tema e descritiva, conforme Gil (2002), pois é uma pesquisa que tem como objetivo a descrição das características do tema estudado. Desse modo, além de se familiarizar a respeito dos processos pedagógicos de alfabetização e letramento na Educação de Jovens e Adultos, pretendeu-se descrever como ela ocorre na perspectiva do professor.

Já em relação aos procedimentos técnicos, trata-se de uma pesquisa de campo que, de acordo com Praça $(2015$, p. 76) é "aquela baseada na coleta de fenômenos que ocorrem na realidade a ser pesquisada.". Como instrumento de coleta de dados utilizou-se a entrevista semiestruturada, que segundo Gil (2002, p.126) é: “[...] aquela que parte de certos Saberes Pedagógicos, Criciúma, v. 5, n³, setembro/dezembro 2021.- Curso de Pedagogia- UNESC 
conhecimentos básicos apoiados em teorias e hipóteses, que interessam à pesquisa, e que, em seguida, oferecem amplo campo de interrogativas, fruto de novas hipóteses que vão surgindo à medida que se recebem as respostas do informante.”.

Sendo assim, foram elaboradas 10 perguntas semiabertas, e os sujeitos da pesquisa foram 02 (duas) professoras que atuam em um Centro de Educação de Jovens e Adultos, em um município pertencente à região da AMREC. As professoras foram convidadas e após seus aceites, ficaram marcadas as entrevistas, que aconteceram no mês de setembro de 2020.

Antes da realização das entrevistas, as professoras assinaram o termo de consentimento, o qual declararam que aceitavam participar da pesquisa, mas não seriam identificadas. Os termos de consentimento originais estão em posse da pesquisadora. Para coletar os dados utilizou-se um dispositivo móvel para a gravação de suas falas, Todas as falas foram transcritas e separadas em blocos. As entrevistas aconteceram nos horários propostos pelas professoras, de forma presencial e individual, em que suas identidades foram resguardadas.

Em relação às entrevistadas, durante toda a elaboração da análise, como não poderão ser identificadas, foram-lhes atribuídos nomes de flores, para melhor entendimento, como: Camélia (que significa flor da simpatia) e Magnólia (flor do reconhecimento). Optouse pela escolha de flores por representarem beleza, vida e significado; e a escolha por essas duas, em especial, foi em reconhecimento às professoras entrevistadas e pela forma simpática que receberam e trataram a autora deste trabalho.

\subsection{Perfil das entrevistadas}

Nesta sessão, buscou-se conhecer o perfil das professoras entrevistadas e a turma que trabalham. Para isso, questões que nortearam este estudo foram relacionadas à formação dessas professoras, ao tempo de atuação, às turmas e se participam de formação continuada.

\section{Quadro 1: Perfil das Entrevistadas}

\begin{tabular}{|l|l|l|l}
\hline Educadoras & Formação Acadêmica & Tempo de atuação na EJA & Turma de atuação
\end{tabular}

Saberes Pedagógicos, Criciúma, v. 5, n³3, setembro/dezembro 2021.- Curso de Pedagogia- UNESC 


\begin{tabular}{|l|l|l|l|}
\hline Magnólia & Pedagogia & 14 Anos. & $1^{\circ}, 2^{\circ}$ e $3^{\circ}$ ano \\
\hline Camélia & Pedagogia e Pós Graduação. & 17 Anos. & $4^{\circ}$ e $5^{\circ}$ ano \\
\hline
\end{tabular}

Fonte: Dados de pesquisa, 2020.

Como podemos observar, as professoras entrevistadas trabalham com turmas dos anos iniciais do ensino fundamental e são professoras titulares da turma. Quanto a sua formação profissional, as duas possuem graduação em Pedagogia e Magnólia possui pósgraduação, trabalhando com alunos na EJA há dezessete anos. Já Camélia, possui quatorze anos de experiência na EJA, demonstrando assim, expressiva experiência de trabalho nessa modalidade de ensino.

Quanto à formação continuada, ambas afirmaram que participam das formações que a Secretaria Municipal oferece, além de estarem sempre presentes nos encontros oferecidos semestralmente pelo Centro de Educação de Jovens e Adultos de um município pertencente a região da AMREC. De acordo com Saviani (2007), a formação continuada só tem sentido de verdade, quando a prática e a teoria caminham juntas, e observa: "a prática igualmente depende da teoria, já que sua consistência é determinada pela teoria" (SAVIANI, 2007, p. 3). Um professor que está sempre estudando, pesquisando novas práticas para trabalhar com seus alunos, faz com que sua aula se torne um espaço prazeroso, significativo e de muito aprendizado.

\subsubsection{Compreendendo as práticas pedagógicas das professoras}

Iniciou-se a entrevista questionando as professoras sobre por que escolheram trabalhar na EJA - Educação de Jovens e Adultos. Camélia respondeu assim: "gosto de alfabetizá-los, de ensinar eles a ler e escrever, pois é para isso que eles voltam para a escola. Não frequentaram a escola na idade certa, por vários motivos"; e Magnólia disse que "ajudar estas pessoas, que não sabem ler e escrever, é dar significado, é contribuir na mudança de vida delas. Isso é muito bom, me realiza”. Ambas responderam de forma semelhante, lembrando as palavras da autora Cortada (2013, p.7) que define a EJA assim: "é uma Saberes Pedagógicos, Criciúma, v. 5, n³3, setembro/dezembro 2021.- Curso de Pedagogia- UNESC 
modalidade de Educação Básica, cujo objetivo é o de favorecer oportunidades de estudo a essa parcela da sociedade que não teve acesso aos estudos na idade própria".

Aproveitou-se a fala anterior da professora Camélia quando falou "Vários motivos" e perguntamos para as duas entrevistadas, quais motivos seus alunos alegam para ter retornado à escola? Mais uma vez as respostas foram parecidas. Magnólia falou muito e destacou: "Ler livros, revistas, conta de luz, pegar ônibus, usar o caixa do banco, fazer compras". Camélia disse serem muitos, mas citou os que mais aparecem na sua turma: “escrever, ler jornal, revista, celular, salmos na igreja, caixa do remédio, ensinar a lição para os filhos, tirar a carteira de motorista, não precisar da ajuda dos outros para ler para eles".

Entende-se que a volta de um jovem para a escola não acontece de maneira simples, e de um adulto e idoso então, os desafios devem ser muito maiores. Mas segundo Ribeiro (2001) foi só após a promulgação da CF - Constituição Federal de 1988 que:

O ensino fundamental foi estendido aos cidadãos de todas as faixas etárias, o que nos estabelece o imperativo de ampliar as oportunidades educacionais para aqueles que já ultrapassaram a idade de escolarização regular. (RIBEIRO, 2001, p. 16)

A CF de 1988, além de estender a faixa dessa clientela, se preocupou com a qualificação pedagógica de programas de educação de jovens, justificando que só assim, “a escolarização tardia de milhares de cidadãos não venha a se configurar como mais uma experiência de fracasso e exclusão" (BRASIL, 1988, p. 209).

Questionada sobre qual a concepção de ensino que embasam suas práticas pedagógicas, respondeu assim Camélia: “depende do conteúdo da turma, mas, procuro trabalhar mais dentro da concepção histórico cultural". Magnólia, tendo o mesmo questionamento, relatou o seguinte: “A gente se esforça para ser construtivista, mas, os alunos, eles não gostam muito do material didático, eles gostam de copiar do quadro, fazer cópia no caderno, como inicio a alfabetização da maioria, tenho que ser mais tradicional nos métodos de ensino".

Percebe-se, nas falas das professoras, que elas citam as teorias Progressistas de aprendizagens como as mais adequadas para seus alunos, lembrando Freire (1974) quando diz que a aprendizagem acontece somente por meio da relação entre o sujeito e sua realidade,

Saberes Pedagógicos, Criciúma, v. 5, n³, setembro/dezembro 2021.- Curso de Pedagogia- UNESC 
caso contrário esses alunos não alcançarão meios de transformar a si próprios e o mundo. $\mathrm{Na}$ resposta da professora Magnólia apareceu, quando se referiu aos alunos, resquícios mais acentuados de práticas tradicionais, nos levando a pensar que não esqueceram da escola que frequentaram quando crianças, mesmo sendo por pouco tempo.

Quando questionadas sobre como elaboram o planejamento, ambas responderam que fazem o planejamento geral no início do ano e Camélia explicou: “É assim, no início do ano nós nos reunimos e escolhemos uma pauta para ser discutida durante o ano, vamos supor que seja a família. Eu tenho o ano todo pra discutir sobre a família, em todos os segmentos: português, matemática, história, geografia e ciências".

A professora Magnólia salienta que os alunos da EJA precisam de mais fixação, “tem que repetir, com o adulto a gente repete os assuntos bem mais, até eles fixarem". Ambas também concordaram que cada ano recebem uma realidade diferente de alunos, e que nos primeiros dias de aula realizam uma sondagem nas turmas, para conhecerem e adaptarem os temas planejados à realidade dos alunos.

Nota-se, que mesmo aparecendo a palavra "fixação", elas procuram respeitar a realidade dos educandos na elaboração das práticas pedagógicas. Cortada (2013, p.187) aponta que "O professor da EJA ao trabalhar com ênfase na realidade vivida pelos alunos, a educação se torna elemento transformador e de conscientização".

De acordo com Freire (1990, p. 33) A alfabetização e a educação, de modo geral, são expressões culturais. "Não se pode desenvolver um trabalho de alfabetização fora do mundo da cultura, porque a educação é, por si mesma, uma dimensão de cultural". O autor se refere a cultura como manifestação, ação, produção de um grupo de pessoas, que ocorre por meio de linguagens e pode ser identificado pela forma de falar, agir, pensar de uma pessoa ou de um grupo (FREIRE, 1990).

Em seguida, questionamos se elas trabalham as atividades de alfabetização dentro da perspectiva de alfabetização e letramento. Ambas responderam que na maioria das vezes sim. E justificaram o sim argumentando que:

\section{Camélia:}

Saberes Pedagógicos, Criciúma, v. 5, n³, setembro/dezembro 2021.- Curso de Pedagogia- UNESC 
Como a minha turma é $4^{\circ}$ e $5^{\circ}$ ano, procuro trabalhar mais com textos dos diferentes gêneros, ajudo eles a interpretar, a ler, copiam do quadro. Muitas vezes, procuro partir do que conhecem, por exemplo, quando vou trabalhar sobre o meio ambiente, primeiro sentamos em círculo e conversamos bastante sobre o que sabem e como é no bairro e cidade, sobre o tema, depois passo um texto no quadro ou entrego um texto sobre o assunto, mostro imagens do Brasil e do Mundo e assim segue a semana.

Magnólia:

Faço um pouco de tudo. Minha turma é bem diferente, tenho alguns que conhecem as letras do alfabeto, outros juntam sílabas, alguns escrevem o seu nome; palavras poucos escrevem e leem frases. Trabalho seus nomes, dos familiares, nome das profissões, frutas e comidas que mais gostam de comer e assim vai...

Emendou-se a conversa e foi perguntado como era feita a seleção de textos utilizados como práticas de alfabetização e letramento nas suas atividades. Cada uma respondeu adequadamente à sua turma. Camélia disse que sempre lembra que eles sabem e conhecem muitas coisas e além de textos que já falou acima, de acordo o assunto utiliza:

Receitas culinárias, conta de luz e água. Já trabalho português, matemática, a cultura da receita... músicas eles gostam de ouvir, cantar, interpretar a letra, escolho cantores que conhecem e gostam, já trabalho a biografia deles, região do Brasil que mora e tudo mais que vão perguntando. Nas segundas-feiras início sempre perguntando o que fizeram no final de semana, escutamos todos falarem, depois refletimos e em seguida partimos para o registro. (CAMÉLIA, entrevista para análise de dados, 2020)

Magnólia respondeu dizendo que sabe que seria melhor se começasse mostrando textos para eles, mas eles se assustam e querem aprender a ler e escrever logo e sabem que devem usar as letras para isso, aí acaba iniciando:

\begin{abstract}
Mostrando as vogais, depois as consoantes, junto algumas, eles copiam no caderno e leem. A cópia é uma coisa que eles gostam muito de fazer, o método silábico facilita a aprendizagem desses alunos, pelo menos os meus. Só depois de um bom tempo, quando eles já dominam bem as sílabas, aí trabalho seus nomes, utilizo um crachá, certidão de nascimento, leio cada uma certidão individualmente... leva uma semana, mas prefiro assim, eles gostam mais, e eu fico sabendo um pouco sobre sua vida e sua família. (MAGNÓLIA, entrevista para análise de dados, 2020)
\end{abstract}

A seguir será compartilhada a análise das respostas das entrevistadas sobre as práticas utilizadas para a alfabetização, objetivo principal da pesquisa.

Percebe-se, pelas respostas das entrevistadas, que utilizar a realidade na qual os Saberes Pedagógicos, Criciúma, v. 5, n³ , setembro/dezembro 2021.- Curso de Pedagogia- UNESC 
alunos pertencem, levar elas em consideração, partir daquilo que faz parte de seu cotidiano, em alguns momentos está presente em suas falas. Essa fala de respeitar a realidade e o conhecimento do aluno está presente quando Cortada (2013, p. 187) aponta que: "tais conhecimentos não podem ser desprezados num processo de ensino que priorize a transformação e conscientização do homem para que se torne agente de sua existência".

Contudo, Schwartz (2010, p.50), não deixa esquecer que trabalhar a partir da realidade do aluno "não significa que temas que não fazem parte da realidade material dos alunos não devam ser abordados, mas sim que sejam planejadas condições para promover reflexões críticas sobre estes conteúdos, oportunizando o conhecimento, a compreensão e o desenvolvimento de estratégias de alternativas de solução". Quanto a expressão da Professora Magnólia quando disse "Eu faço um pouco de tudo", Schwartz (2010, p. 58) sinaliza que esta prática tem a ver com o professor que precisa revisar sua teoria e cita, "trata-se sim de compreender a teoria que embasa a prática, em busca da clareza necessária para desempenhála".

Sabe-se que durante muitos anos, a aprendizagem da escrita no nosso país era realizada codificando-se e decodificando-se para só depois tentar compreendê-la e talvez usála. Segundo Schwartz (2010, p. 48), os professores que "pensam e desenvolvem sua prática metodológica iniciando com o alfabeto, primeiro com as letras e depois formando sílabas simples (ba,be,bi,bo,bu), explicando oralmente e pedindo para os alunos repetirem e copiarem do quadro, ainda utilizam uma concepção tradicional de ensino.”

De acordo com os estudiosos das concepções progressistas já faz algum tempo que se sabe que não se alfabetiza repetindo e memorizando palavras sem sentido e significado para o sujeito aprendiz. "Sabe-se que se aprende a ler e escrever, lendo e escrevendo, pensando e atribuindo significado à escrita (FERREIRO \& TEBEROSKY, 1985, p. 47)”.

Segundo Freire (2002), o termo alfabetizar está ligado a leitura de mundo, entrelaçando realidade com linguagem, compreendendo o texto como relação entre a escrita e o contexto. Percebe-se desse modo, por que "somente" a habilidade de codificar e decodificar um sistema tradicional não é suficiente para atender a complexidade do conceito de alfabetização, e vai além, dizendo que "alfabetizar é o que torna a pessoa capaz de ler, 
produzir e compreender qualquer tipo de texto que desejar e/ou necessitar". (ALBUQUERQUE, 2007, p.59).

Sobre como é feita a seleção dos textos a resposta da entrevistada Magnólia, nos levou a retomar o conceito etimológico de alfabetizar, que significa "levar a aquisição do alfabeto", o que deixa o termo reduzido a uma estratégia mecânica, articulada com a habilidade de codificar e decodificar grafemas e fonemas. (SCHWARTZ 2010).

A entrevistada Camélia, desde suas falas iniciais, aproximou-se dos estudiosos da alfabetização chamados de progressistas e já citou a utilização de textos para trabalhar suas práticas de alfabetização. Quanto a seleção de textos, mostrou utilizar diferentes gêneros textuais, articulado aos conteúdos e ao contexto social do aluno.

Suas falas nos levam a refletir o que Leal apresenta, quando sugere diversas práticas para os professores trabalharem com textos (Leal, 2010, p.75):

[...] Leitura cotidiana pelo professor de um texto em voz alta. Esse texto pode ser, uma música, uma poesia, uma notícia do jornal da cidade, salmo bíblico, biografia de um artista conhecido, uma receita culinária, uma receita médica entre tantos outros, procurando atender os interesses e necessidades cognitivas, culturais e sociais dos alunos da EJA. Complementa sua sugestão lembrando que, diariamente, após cada leitura, o professor deve oportunizar aos educandos a interpretação e discussão do mesmo, afim de alcançar o objetivo proposto para o tema.

Ao final da entrevista, questionadas sobre como estão trabalhando a alfabetização nesse período de pandemia ${ }^{4}$, Camélia contou que está bem difícil esta questão. "Os que já sabiam ler, eles se viram, assim como já faziam em sala. Agora a alfabetização a gente nem sabe se é eles que estão fazendo. Eu tinha cinco alunos que não conheciam nem o alfabeto e agora estão fazendo as atividades. Eles não aprenderam do dia para a noite, então, provavelmente não são eles que fazem.”.

Magnólia conta, também, sobre a dificuldade de trabalhar nesse período. "Como já conheço eles, posso dizer que $50 \%$ não são eles que estão fazendo, a letra é muito redondinha e bonitinha. Aí comparo com toda a semana quando eles fazem a devolutiva das atividades na escola, não fecha..."

Esse período atípico que se vive fez com que muitas coisas mudassem, e na educação isso não se torna diferente. Foi possível perceber, por meio das respostas das

\footnotetext{
${ }^{4}$ Ocasionado pela COVID-19, que assolou o Brasil. As aulas foram mediadas por recursos tecnológicos Saberes Pedagógicos, Criciúma, v. 5, n³, setembro/dezembro 2021.- Curso de Pedagogia- UNESC
} 
professoras que trabalhar dessa forma, como todos estão trabalhando, dificulta bastante, principalmente na EJA, onde muitos não têm acesso a internet ou não utilizam esses meios de comunicação. Os discentes sentem a falta do diálogo, do toque, do afeto, dessa relação estabelecida entre o professor, o aluno e os colegas.

\section{CONCLUSÃO}

Ao longo dos anos muitas mudanças ocorreram na área educacional, principalmente se tratando da alfabetização. Atualmente, o conceito de alfabetização em todas as modalidades de ensino, não pode mais estar relacionado somente à memorização, voltado para a codificação e decodificação, em que o sujeito assume um papel passivo, não interpreta ou questiona as coisas. A sociedade contemporânea exige cidadãos que interajam e questionam na sua realidade, nesse sentido a escola precisa também estar atualizada, com métodos e projetos diversificados, trabalhando assim para uma aprendizagem efetiva e significativa.

Deste modo, o intuito da pesquisa foi analisar as práticas pedagógicas de alfabetização de duas professoras da EJA dos anos iniciais em um município da AMREC. Por meio das entrevistas, foi possível identificar como trabalham a alfabetização e se a mesma ocorre na perspectiva do letramento. Deste modo, buscou compreender como de fato esse ensino ocorre no contexto da sala de aula, e ainda, motivar melhores e mais efetivas práticas educacionais, com o intuito de contribuir com uma aprendizagem que tenha sentido para aquele estudante.

Assim, foi concebível observar por meio das entrevistas que as duas professoras buscam, algumas vezes, levar em consideração as práticas de letramento que seus alunos trazem consigo ao ingressarem na Educação de Jovens e Adultos. Vê-se assim, que quando as entrevistadas trabalham determinado assunto, buscam partir daquilo que o aluno conhece e que faz parte do seu cotidiano, de modo com que os alunos façam a associação do que está aprendendo com aquilo que já sabe.

Entretanto, as duas professoras utilizam concepções pedagógicas distintas, onde Camélia mostrou trabalhar mais dentro da perspectiva de alfabetizar letrando, enquanto Saberes Pedagógicos, Criciúma, v. 5, n³3, setembro/dezembro 2021.- Curso de Pedagogia- UNESC 
Magnólia trabalha a alfabetização de uma forma mais tradicional, baseando-se na codificação e decodificação.

Por sua vez, fica evidente que mesmo em momentos trazendo essa realidade para dentro da sala, isso não ocorre em todos os momentos da alfabetização. Em relação as metodologias utilizadas, Camélia mostrou trabalhar com textos e os diferentes gêneros textuais enquanto Magnólia pontuou ainda a questão de juntar as letras e fazer a cópia do quadro, não utilizando assim as práticas de letramento nesse processo.

Percebe-se que os alunos que frequentam a modalidade EJA são jovens, adultos e idosos, de diferente faixa etária e cultura. Assim, esses alunos trazem muitos conhecimentos para dentro da sala de aula e o professor pode utilizar todas essas práticas de letramento para envolver o aluno ainda mais no processo de alfabetização.

A vista disso, como não é possível afirmar que todas as educadoras trabalham nessa perspectiva de ensino, é muito importante o olhar especial para essa modalidade, para que assim possa se findar boas práticas de alfabetização e que façam com que os educandos saibam e busquem sempre os seus direitos perante a sociedade e possam também cumprir com os seus direitos.

Por ser uma modalidade de ensino relativamente nova, não são muitas as capacitações para os profissionais dessa área. Isso faz com que, muitas vezes, esse ensino ocorra de forma similar ao ensino regular, e tudo aquilo que o aluno traz para a sala de aula não seja utilizado de modo para contribuir para uma aprendizagem concreta e significante.

Ao finalizar-se esta pesquisa, foi possível perceber que na EJA, apesar das mudanças já ocorridas, é preciso uma longa e contínua mudança, a fim de que o sujeito que frequenta a EJA encontre espaço e oportunidades que em outro momento não foi possível, e que é um direito do cidadão.

Cresce a cada dia o número de alunos matriculados na EJA, e para tanto, é necessário que esse ensino cresça também, atualizando-se e procurando novas metodologias para ter-se uma educação de qualidade. Para isso, as práticas de alfabetização devem caminhar juntas com as práticas de letramento, para que o aluno tenha acesso à leitura e a escrita e consiga fazer uso dela nas suas práticas sociais. Entretanto, é fundamental a 


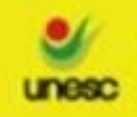

continuação de pesquisas nesse campo, a fim de que mais s professores utilizem práticas de alfabetização que considerem as experiências de letramentos que os alunos já possuem.

\section{REFERÊNCIAS}

ALBUQUERQUE, Eliana Borges Correia de (org.). A alfabetização de jovens e adultos em uma perspectiva do letramento. Belo Horizonte: Autêntica, 2010.

ALBUQUERQUE, Eliana Borges Correia de. Desafios da educação de jovens e adultos: construindo práticas de alfabetização. 2. São Paulo: Autêntica 2007.

ALBUQUERQUE, Eliana Borges Correia de; FERREIRA, Andréa Tereza Brito. A construção/fabricação de práticas de alfabetização em turmas de Educação de Jovens e Adultos (EJA). Santa Maria, v. 33, n. 3, p. 425-440, set./ dez. 2008. Disponível em: <https://periodicos.ufsm.br/reveducacao/article/view/82/56>. Disponível em: 04 out 2020.

BARROS, Flavia Regina de. Alfabetização e letramento na educação de jovens e adultos./ Flavia Regina de Barros. Campinas, SP; [s. n], 2011. Disponível em: http://repositorio.unicamp.br/jspui/bitstream/REPOSIP/251233/1/Barros_FlaviaReginade M.pdf . Acesso em: 23 out 2020.

BRASIL. Constituição da República Federativa do Brasil de 1988. Brasília, DF: Presidência da República. Disponível em: <http://www.planalto.gov.br/ccivil_03/constituicao/constituicao.htm>. Acesso em 21 out 2020.

BRASIL. Lei n $^{\circ}$ 9.394, de 20 de dezembro de 1996. Estabelece as diretrizes e bases da educação nacional. Brasília, DF: Presidência da República, 1996. Disponível em: <http://portal.mec.gov.br/seesp/arquivos/pdf/lei9394_ldbn1.pdf>.Acesso em: 12 out. 2020

CORTADA, Silvia (org). EJA: Educação de Jovens e Adultos e seus diferentes contextos. Jundiaí, SP: Paco, 2013.

FREIRE, Paulo. A importância do ato de ler: em três artigos que se completam. São Paulo: Autores Associados: Cortez, 1989.

FREIRE, Paulo. Alfabetização: leitura da palavra leitura da palavra/ Paulo Freire, Donaldo Macedo. Rio de Janeiro: Paz e Terra, 1990.

FREIRE, Paulo .Pedagogia da autonomia: saberes necessários à prática educativa. 25. ed. São Paulo: Paz e Terra, 2002b. 


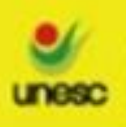

FREIRE, Paulo. Pedagogia do Oprimido. São Paulo: Paz e Terra, p.57-76. 1974

FERREIRA, Aurélio Buarque de Holanda. Mini Aurélio: o dicionário da língua portuguesa/ Aurélio Buarque de Holanda Ferreira; coordenação de edição Marina Baird Ferreira. - 8. Es. - Curitiba: Positivo, 2010. 960 p.

FERREIRO, Emilia; TEBEROSKY, Ana. Psicogênese da língua escrita. Porto Alegre: Artes Médicas, 1985.

GADOTTI, Moacir. A educação contra a educação. Rio de Janeiro: Paz e Terra, 1973.

GIL, Antonio Carlos. Como elaborar projetos de pesquisa. 4. ed. São Paulo: Atlas, 2002.

HADDAD, Sergio; DI PIERRO, Maria Clara. Escolarização de jovens e adultos. Revista Brasileira de Educação. 2000, n. 14, p 108-139.

LEAL, T. F. Condições de produções de textos no ensino de jovens e adultos. In: Anais da 26a Reunião Anual da ANPED. Caxambu (MG), 2003.

LEAL, Telma Ferraz (org.). Alfabetizar letrando na EJA: fundamentos teóricos e propostas didáticas. Belo Horizonte: Autêntica editora, 2010.

PINTO, Álvaro V. Sete lições sobre Educação de Adultos. 10. ed., São Paulo: Cortez, 1994.

PRAÇA, Fabíola Silva Garcia. Metodologia da pesquisa científica: organização estrutural e os desafios para redigir o trabalho de conclusão. Diálogos acadêmicos, n. 1, p. 72-78, jan./jun., 2015. Disponível em:

<http://www.uniesp.edu.br/sites/_biblioteca/revistas/20170627112856.pdf>. Acesso em: 03 de nov. de 2020.

RIBEIRO, Vera M. M. (org.) Educação de Jovens e Adultos. Novos Leitores. Novas Leituras. São Paulo: Ação Educativa, 2001.

SANTOS, Maria de Fátima Ribeiro; SANTOS, Saulo Ribeiro dos. Metodologia da pesquisa em educação. São Luiz: Uemanet, 2010. 67 p. Disponível em:

http://nead.uesc.br/arquivos/pedagogia/metodologia-da-pesquisa-em-educacaocompleto.pdf> Acesso em 11 nov 2020.

SAVIANI, Dermeval. Pedagogias: o espaço da educação na universidade. In: Cadernos de Pesquisa. São Paulo, 2007, v.37, n. 130.

SOARES, Magda. Alfabetização e letramento. 2. Ed. São Paulo: Contexto, 2003. 
SOARES, Magda. Letramento: um tema em três gêneros. Magda Soares. -3. ed. - 2. Reimp. -Belo Horizonte: Autêntica Editora, 2001.

SOARES, Magda. O letramento e a alfabetização: qual é a diferença entre a alfabetização de jovens e adultos? Letra A- O jornal do alfabetizador, v. 2, jun/jul. 2006.

SCHWARTZ, Suzana. Alfabetização de Jovens e Adultos: teoria e prática. Petrópolis, RJ: Vozes, 2010. 